\title{
Elaboração e Caracterização de Biofilmes de Quitosana para Aplicação em Maçãs Cortadas
}

\section{Tayane H. Siqueira \& Roberta Signini}

Aquitosana é um polímero com propriedades funcionais importantes na área alimentar tais como biocompatibilidade, atividade antimicrobiana e antioxidante, não-toxicidade e capacidade de formar filmes. O objetivo deste estudo foi produzir e caracterizar os biofilmes de quitosana para ser utilizado como cobertura em maçãs cortadas. Os filmes de quitosana foram obtidos através do método casting e caracterizados quanto a sua espessura, permeabilidade ao vapor de água e biodegradação. Os filmes de quitosana apresentaram espessura variada e crescente conforme aumentava-se a concentração da solução de quitosana. A permeabilidade ao vapor de água foi menor à medida que se aumentou a concentração de quitosana. Quanto a biodegradação foi observada que os filmes degradaram parcialmente durante os dez dias de experimento. Solução de quitosana de $5 \mathrm{~g} / \mathrm{L}$ foi utilizada como cobertura em maçãs cortadas, sendo que o biofilme de quitosana em maçã apresentou como boa cobertura no controle de vapor de água e ação antifúgica.

Palavras-chave: quitosana; filmes; maçãs.

Chitosan (QTS) is a polymer with functional properties important in the food area, such as biocompatibility, antimicrobial and antioxidant activities, nontoxicity, and the ability to form films. The objective of this study was to produce and characterize biofilms chitosan to be used as a protective cover on cut apples. The chitosan films were obtained by casting method and characterized as its thickness, permeability to water vapor and degradation. The chitosan film had a thickness varied and increased with increase in the concentration of the chitosan solution. The permeability to water vapor was smaller as they increase the concentration of chitosan. The biodegradation was observed that the films partially degraded during the ten days of the experiment. Chitosan solution of 5 $\mathrm{g} / \mathrm{L}$ was used as a cover clipped on apples, and the biofilm on apples chitosan showed good coverage as in the control of water vapor and antifúgica action.

Keywords: chitosan; film; apple. 


\section{Introdução}

Recentemente, tem havido grande interesse no desenvolvimento de filmes ou coberturas biodegradáveis, principalmente pelo impacto ambiental provocado pela degradação muito lenta das embalagens convencionais de alimentos. Além disso, há oportunidades para a criação de novos mercados para matérias-primas renováveis, derivadas de produtos agrícolas, na produção de filmes ${ }^{1,2}$.

A quitosana tem sido usada como um material importante na ciência e na indústria por suas propriedades únicas, uma vez que oferece vantagens potenciais como matéria prima para a produção de filmes, coberturas e aplicações plásticas; além de ser biodegradável, bioconservante e renovável ${ }^{3}$, com uma boa eficácia na preservação da qualidade microbiológica do alimento ${ }^{4}$. Filmes e revestimentos à base de quitosana, polissacarídeo obtido da desacetilização da quitina, têm sido usados como revestimento de frutas com o objetivo de aumentar a vida de prateleira, sem comprometer sua qualidade $^{5,6}$. A quitosana também é reconhecida como segura quando usada como revestimento de acordo com o NATIONAL TOXICOLOGY PROGRAM ${ }^{7}$. Além disso, a quitosana é considerada uma substância GRAS (Substances Generally Recognized as Safe Substâncias Geralmente Reconhecida como Segura) pelo FDA (Food and Drug Administration) ${ }^{8}$ e de baixa toxicidade para a saúde humana'.

A quitosana, na forma de filmes em frutos ou vegetais, destaca-se por sua capacidade de atuar como uma barreira à perda de umidade, controlar a respiração de frutos ou vegetal e apresentar alto potencial antimicrobiano, além de prevenir o escurecimento enzimático, ressaltando-se que esta é biodegradável o que a torna "ambientalmente correta" ${ }^{10}$. Assim, os biofilmes a base de quitosana como embalagens ativas, além de atuarem como uma barreira a agentes externos apresentam uma série de funções desejáveis à manutenção da qualidade do vegetal ou fruto revestido. Apresenta como uma das vantagens, sobre a embalagem convencional, o fato da quitosana apresentar propriedades como agente antimicrobiano e antioxidante atendendo a atual demanda por alimentos minimamente processados e livres da incorporação de conservantes químicos ${ }^{10}$.
Filmes de quitosana pode atuar como uma barreira a elementos externos tais como umidade, óleo e gases, notadamente etileno, dióxido de carbono e oxigênio e, consequentemente, pode conferir maior proteção ao produto revestido, estendendo sua vida útil ${ }^{11}$. Conforme Cia et al. ${ }^{12}$, a habilidade da quitosana em propiciar condições de atmosfera modificada, determinando o atraso do processo de amadurecimento, pode estar relacionada à ação do produto sobre a parede celular do hospedeiro, visto que, durante o processo de amadurecimento, os tecidos perdem firmeza em função do aumento da solubilidade das substâncias pécticas, ou protopectinas, presentes na parede. Isso determina o aumento da suscetibilidade da célula hospedeira à maceração promovida pelas enzimas pectolíticas liberadas pelo patógeno.

A ação antifúngica e antibacteriana de filmes de quitosanas já foi constatada por diversos autores ${ }^{13-16}$ que utilizou filmes de quitosana no recobrimento de uva "itália" verificou que este suprimiu o crescimento de Botrytis cinérea, o mofo cinzento. Assis e Alves ${ }^{17}$ verificaram ação antifúngica de um filme de quitosana no recobrimento de maçãs. Ainda, a quitosana pode induzir a atividade da fenilalanina amônia-liase (FAL). Devido à sua habilidade de formar um filme semipermeável, pode modificar a atmosfera ao redor do produto e diminuir as perdas por transpiração e desidratação dos frutos, além de atrasar o amadurecimento e o escurecimento enzimático de alguns frutos.

$\mathrm{Na}$ agricultura, a quitosana tem sido aplicada como biofilme na preservação de frutas, legumes e sementes contra a deteriorização por microrganismos, para estimular o sistema imune da planta, proteger a planta contra o ataque de patógenos e favorecer o seu crescimento e consequentemente aumento da produção vegetal ${ }^{18}$. Esse biopolímero pode interferir diretamente no crescimento de vários fungos fitopatógenos $\mathrm{e}$ bactérias, apresentando efeito fungiostático e/ou fungicida, e bacteriostático e/ou bactericida.

A literatura ${ }^{19-24}$ relatam que a quitosana pode induzir mudanças morfológicas, alterações estruturais e desorganização molecular em fungos. Também pode ativar várias respostas de defesa no tecido vegetal ocasionando: lignificação, indução de síntese de calose, eliciação da produção de fitoalexinas, de peróxido de hidrogênio $\left(\mathrm{H}_{2} \mathrm{O}_{2}\right)$, acúmulo de quitinase, síntese de 
inibidores de proteinase, e induzir a atividade da fenilalanina amônialiase $-\mathrm{FAL}^{18}$.

$\mathrm{Na}$ fruticultura o uso da quitosana foi avaliado em diversas espécies como em citros, cuja aplicação inibiu o crescimento de Penicillium digitatum ${ }^{25}$, e apresentou potencial no controle de Guignardia citricarpa, agente causal da mancha preta dos citros, sendo observado aumento da atividade das enzimas quitinases, glucanases, peroxidases e polifenoloxidase ${ }^{26}$. O uso de quitosana nas concentrações de 1,2 e $4 \%$ reduziu significativamente a severidade de antracnose em frutos de mamão, sendo que a $4 \%$ reduziu também a incidência da podridão. Nas concentrações de 2 e $4 \%$ os frutos não amadureceram normalmente, permanecendo com coloração da casca verde até o final do amadurecimento, sendo no entanto, recomendado pelos autores a concentração de $1 \%$ como opção viável para tratamento pós-colheita de mamão ${ }^{27}$. Em maçãs, quitosana inibiu $P$. expansum e $B$. cinerea $^{25}$.

Em morangos, aplicações pré-colheita e pós-colheita de quitosana reduziram podridões causadas por B.cinerea, além de manter maior firmeza dos frutos retardando a maturação ${ }^{20}$. O efeito da redução de podridões em morangueiro sobre Botrytis cinerea e Rhizopus stolonifer também foi observado por EL GHAOUTH et al. ${ }^{19} \mathrm{O}$ efeito antimicrobiano de quitosana foi relatada em morangos minimamente processados ${ }^{22}$.

Em kiwi o uso de quitosana comparado com 3 fungicidas sobre Botrytis cinerea, mostrou-se com limitada eficiência, porém in vitro teve efeito na redução da taxa de germinação dos esporos, tamanho e crescimento do tubo germinativo ${ }^{28}$. Em pêssegos, o uso de quitosana em pós-colheita reduziu podridões quando aplicado em concentrações entre $0,25 \%$ e $1 \%{ }^{29}$. A aplicação de quitosana em videira, em fase pré-colheita, atuou de forma eficiente no controle de Botrytis cinerea na cv.Itália na pós-colheita, induzindo a maior atividade da enzima PAL ${ }^{15}$.

$\mathrm{Na}$ olericultura quitosana vem sendo largamente estudada, como em alface minimamente processada, de forma que prolongou a vida pós-colheita, estendendose por quatro dias o período de armazenamento ${ }^{22}$. Em pepinos, houve controle da podridão de raízes causada por Pythium aphanidermatum, indução de respostas de defesas, incluindo a indução de barreiras estruturais nos tecidos das raízes e estímulo das hidrolases (quitinases e $\beta$-1-3-glucanases) tanto nas raízes como nas folhas, além de não ter causado fitotoxidade na planta ${ }^{30}$. Em pimenta, o uso de quitosana sobre Botrytis cinerea causou severos danos citológicos a hifa, inibindo a habilidade do patógeno de colonizar os tecidos ${ }^{20}$. Em feijoeiro, esse polissacarídeo foi capaz de reduzir em até $70 \%$ a severidade da antracnose causada por Colletotrichum lindemuthianum, além de induzir mecanismos de resistência nas plantas através do incremento da atividade da ß-1,3-glucanase, enzima que atua diretamente nas glucanas presentes na parede celular do fitopatógeno, inibindo o seu desenvolvimento ${ }^{31}$.

O objetivo principal deste trabalho consistiu na preparação e caracterização de filmes comestíveis a base do polissacarídeo quitosana na concentração de $5 \mathrm{~g} / \mathrm{L}$ para aplicação biotecnológica como biofilme/ revestimento em maçã cortada. Utilizou-se cobertura de quitosana para preservação de maças cortadas e verificouse as características físico químicas perda de massa e análise microbiológica qualitativa. Também realizou-se a caracterização dos filmes para compreensão dos resultados experimentais obtidos assim como o conhecimento das principais propriedades funcionais: espessura, permeabilidade ao vapor d'água e biodegradabilidade.

\section{Parte Experimental}

\section{AVALIAÇÃO DO REVESTIMENTO DE FILMES DE QUITOSANA EM MAÇÃS}

A fim de avaliar o efeito do revestimento de filmes de quitosana em maças do tipo Gala com o intuito de verificar o efeito protetor contra fungos e a perda de umidade em maçãs foram realizados os seguintes procedimentos:

\section{Preparação das maçãs}

Foram utilizadas maçãs sadias e de tamanho uniforme do tipo Gala. Os frutos foram lavados com água e sabão neutro, após foram desinfectados por meio de imersão em solução aquosa de hipoclorito de sódio a $0,1 \%$ (v/v) por 15 minutos, lavados em água corrente, seguido da imersão em álcool $1 \%$ por 5 minutos e secos ao ar, à temperatura ambiente.

\section{Solução de quitosana}

A solução filmogênica foi preparada dispersando-se 
a quitosana sob agitação constante em solução $1 \%$ de ácido acético, por 24 horas, sob temperatura ambiente. A solução filmogênica de quitosana apresentava concentração de $5 \mathrm{~g} / \mathrm{L}$. A quitosana utilizada foi um produto comercial da marca Polymar lote 20090930, cujo grau médio de acetilação (\%GA) é de $26,2 \%$.

\section{Adição da solução filmogênica de quitosana em maçãs}

Para recobrir as maçãs foram utilizados dois métodos: por imersão das maçãs em solução de quitosana e por aplicação da solução de quitosana por spray ou pulverização. Os métodos são descritos a seguir:

I) As amostras foram imersas com a ajuda de um suporte metálico na solução filmogênica por dez segundos (Figura 3 a)

II) As amostras foram revestidas com solução aquosa por pulverização, com sistema de pressão manual (spray). (Figura 3 b).
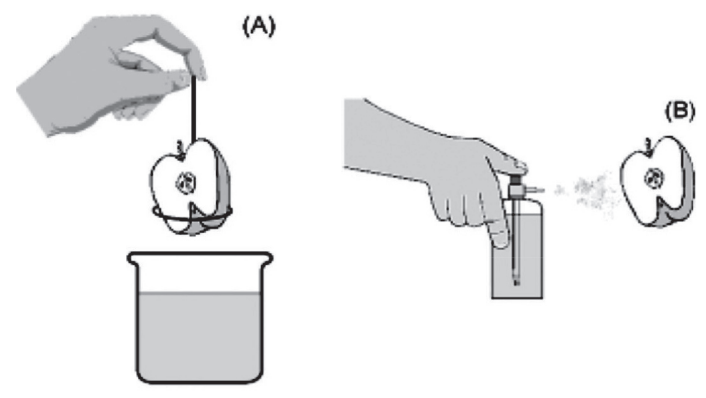

Figura 3. Procedimentos de revestimento adotados: (A) - Imersão e (B) spray ou Pulverização.Fonte: Assis, 2003.

Independente do método utilizado para revestir as maçãs com solução filmogênica de quitosana, escoou - se o excesso do gel, das amostras e após as maçãs foram deixadas secar em condição ambiente por um período de uma hora. Após secagem, formouse uma película aderente ao fruto e este foi pesado e armazenado em estufa à vácuo (Tecnal) por 10 dias, sendo que a cada 24 horas efetuou-se a pesagem do mesmo para acompanhamento da taxa de respiração do fruto Essa análise é obtida por meio da diferença entre as pesagens dos frutos em cada intervalo de tempo e o tempo zero, sendo o resultado expresso em porcentagem. Também se avaliou por fotografias o crescimento microbiológico de fungos. Todas as análises foram feitas em triplicatas.

\section{PREPARAÇÃO DE FILMES DE QUITOSANA}

Os filmes de quitosana foram elaborados segundo o método casting descrita por Monterrey-Quintero e Sobral $^{32}$ e Vicentini ${ }^{33}$, que consiste na desidratação de uma solução coloidal, chamada de solução filmogênica (SF). Esta técnica compreende a aplicação da solução filmogênica em um suporte adequado, seguida de secagem em condições estritamente controladas.

Para a preparação dos filmes de quitosana pelo método Casting, adicionou-se $25 \mathrm{~g}$ de solução filmogênica de quitosana em placas de acrílico de $850 \mathrm{~mm}$ de diâmetro, para posterior secagem a $25^{\circ} \mathrm{C}$ em estufa de circulação e renovação de ar (MARCONI MA 035) por 48 horas ou em dessecador por um período de 5 -10 dias. O controle da massa da solução filmogênica aplicada às placas foi feito em balança analítica (LOGEN Scientific AL 500). Após a formação dos filmes as placas foram condicionadas e/ou mantidas em dessecador contendo sílica, antes de serem caracterizados.

A elaboração dos filmes foi dividida em quatro experimentos os quais se diferem apenas pela concentração da solução filmogênica de quitosana: 5 $\mathrm{g} / \mathrm{L} ; 10 \mathrm{~g} / \mathrm{L} ; 15 \mathrm{~g} / \mathrm{L}$ e $20 \mathrm{~g} / \mathrm{L}$. Em todos os experimentos foram utilizados os mesmos procedimentos de preparo, secagem e condicionamento de filmes, variando apenas as concentrações da solução filmogênica.

\section{CARACTERIZAÇÃO DOS FILMES DE QUITOSANA}

\section{Espessura}

A espessura dos filmes foi medida com micrômetro manual Tesa Isomaster ${ }^{\circledR}(+0,01 \mathrm{~mm})$ modelo Swiss, com sensor de medida de $0,25 \mathrm{~mm}$ de diâmetro em dez pontos aleatórios, considerando-se a espessura dos filmes como uma média entre as dez leituras ${ }^{33}$. A média de 3 filmes de cada tratamento $(5 \mathrm{~g} / \mathrm{L} ; 10 \mathrm{~g} / \mathrm{L} ; 15 \mathrm{~g} / \mathrm{L}$ e $20 \mathrm{~g} / \mathrm{L})$ foi considerada como resposta.

\section{Permeabilidade ao vapor}

A permeabilidade ao vapor de água foi determinada pelo método dessecante com base na norma E96-95 ${ }^{34}$. 
O sistema de permeação consiste de um dessecador de vidro contendo um frasco de polipropileno com capacidade de $80 \mathrm{~mL}$ provido de tampa rosca com furo (2,2 $\mathrm{mm}$ de diâmetro) e anel de látex. A célula de permeação contém sílica gel que foi secado em estufa a $110{ }^{\circ} \mathrm{C}$ no seu interior criando um ambiente seco no seu interior $\left(0 \%\right.$ de umidade relativa) a $25{ }^{\circ} \mathrm{C}$. As células de permeação foram condicionadas dentro de dessecador contendo água destilada ( $100 \%$ de UR) com ambiente equilibrado durante 96 horas antes da análise. A massa do sistema (célula + filme) foi determinada em balança semi-analítica (BIOPRECISA FA2104N) em intervalos de uma hora no primeiro dia, três horas no segundo, terceiro e quarto dia e 8 horas no quinto dia e 12 horas no sexto dia, para verificar a quantidade de vapor de água absorvido e, consequente, aumento de massa neste intervalo de tempo durante (150) horas. As determinações foram realizadas em triplicata.

A taxa de permeabilidade ao vapor de água (Tva, em $\mathrm{g} \mathrm{m}^{-2} \mathrm{~h}^{-1}$ ) foi calculada através da equação (1) abaixo:

$$
\mathrm{T}_{\mathrm{va}}=\frac{\mathrm{g}}{\mathrm{tA}}
$$

Sendo que: Aé a área de permeação, g é o ganho de massa e t o tempo total em horas. $\mathrm{O}$ termo $\mathrm{g} / \mathrm{t}$ foi calculado por regressão linear entre os pontos de ganho de massa e tempo, no regime constante.

Posteriormente, a permeabilidade ao vapor de água $\left(\mathrm{P}_{\mathrm{va}}\right.$, em g.mm.h $\left.\mathrm{h}^{-1} \cdot \mathrm{m}^{-2} \cdot \mathrm{KPa}^{-1}\right)$ foi calculada através da equação (2) abaixo:

$$
\mathrm{P}_{\mathrm{va}}=\mathrm{T}_{\mathrm{va}} \frac{\mathrm{x}}{\Delta \mathrm{P}}
$$

Sendo que: $\mathrm{x}$ é a espessura média dos filmes e $\Delta \mathrm{P}$ é a diferença de pressão de vapor do ambiente contendo sílica gel $\left(0 \mathrm{kPa}\right.$, a $\left.25^{\circ} \mathrm{C}\right)$ e o com água pura $\left(3,17 \mathrm{kPa}\right.$, a $\left.25^{\circ} \mathrm{C}\right)$.

\section{Teste de biodegradação}

A biodegradabilidade dos filmes foi verificada empregando o teste de Sturn desenvolvido com base nas normas da ASTM D-5338 ${ }^{35}$. Tal metodologia foi empregada para quantificar a liberação de $\mathrm{CO}_{2}$ durante a biodegradação aeróbia do polímero em solo compostado. Foi analisado o filme biodegradável de quitosana de concentração $5 \mathrm{~g} / \mathrm{L}$.
$\mathrm{O}$ presente ensaio contou com três sistemas. $\mathrm{O}$ dois primeiros para a análise do biofilme de quitosana $5 \mathrm{~g} / \mathrm{L}$, dado que o ensaio foi realizado em triplicata e um terceiro somente com a amostra do composto orgânico (amostra denominada de controle ou "branco"). O monitoramento do sistema foi realizado durante dez dias a cada $24 \mathrm{~h}$. A quantidade de $\mathrm{CO}_{2}$ produzida na biodegradação foi determinada filtrando-se a vácuo o precipitado de carbonato de bário formado no processo, secando-o e pesando-o ${ }^{36}$.

\section{Resultados e Discussão}

\section{CARACTERIZAÇÃODE FILMES DE QUITOSANA}

Os filmes resultantes das várias concentrações foram bastante similares na aparência e com alterações evidentes na coloração em função do montante de quitosana adicionada. Ligeira mudança na coloração é igualmente observada para concentrações superiores a $15 \mathrm{~g} / \mathrm{L}$, com tendência a um tom amarelado suave. Contudo, os filmes resultantes, independentes da concentração, foram todos transparentes. Os filmes se mostraram contínuos, sem fraturas ou rupturas, flexíveis e de fácil manuseio com boa transparência e brilho, conforme ilustra a Figura 1.

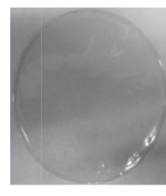

(a)

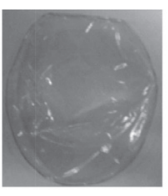

(b)

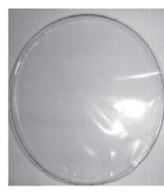

(c)

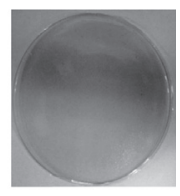

(d)
Figura 1. Ilustração dos filmes de quitosana nas concentrações (a) 5 $\mathrm{g} / \mathrm{L}$, (b) $10 \mathrm{~g} / \mathrm{L}$, (c) $15 \mathrm{~g} / \mathrm{L} \mathrm{e}$ (d) $20 \mathrm{~g} / \mathrm{L}$.

\section{Perda de massa em maça e análise microbiológica}

A perda de massa traduz-se como a expressão percentual da perda de umidade durante o processo de armazenamento do fruto, tornando-se uma variável importante por estar diretamente associada à qualidade do mesmo. Os frutos cobertos com solução filmogênica de quitosana com concentração de $5 \mathrm{~g} / \mathrm{L}$ foi avaliado em triplicata quanto a perda de massa e análise microbiológica e comparadas com o fruto controle, isento de quitosana. A perda de massa em frutos é devida principalmente à perda de água causada pelos processos de transpiração 
e respiração ${ }^{37}$. Foram avaliados os tratamentos: imersão, pulverização e controle e suas respectivas concentrações.

Para o experimento com concentração de $5 \mathrm{~g} / \mathrm{L}$ de quitosana observou-se que o biofilme de quitosana, atuou como uma barreira a perda de umidade do fruto, como descrito no gráfico da (Figura 2). Foi observada diferença significativa quanto à perda de massa entre os tratamentos: Imersão e pulverização após 10 dias de armazenamento em condições não controladas, sob temperatura de $\left(25^{\circ} \mathrm{C}\right.$ $-30^{\circ} \mathrm{C}$ em ambiente de iluminação natural). $\mathrm{O}$ processo de pulverização não apresentou nenhum efeito na perda de massa. Porém, o processo de imersão mostrou-se eficiente quando comparado ao branco.

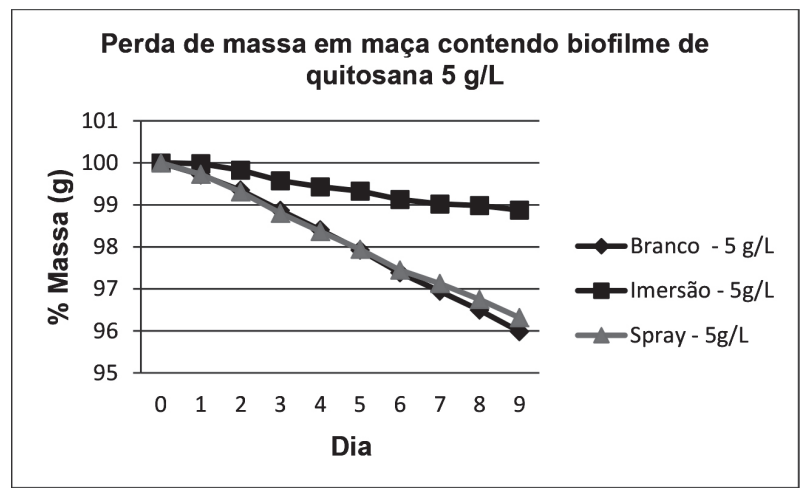

Figura 2. Gráfico da perda de massa de maça contendo biofilme de $5 \mathrm{~g} / \mathrm{L}$

De fato os esses dados estão de acordo com vários estudos presentes na literatura que citam o efeito de quitosana sobre a redução de perda de massa observados em morangos ${ }^{38}$, longan ${ }^{23}$, lichia ${ }^{39}$ e maçãs ${ }^{40}$.

Simultaneamente ao teste físico químico de perda de massa, foi feito o acompanhamento fotográfico da aparência das maçãs cortadas durante 10 dias de armazenamento em estufa à vácuo, para avaliação microbiológica qualitativa.

$\mathrm{Na}$ avaliação microbiológica da amostra de $5 \mathrm{~g} / \mathrm{L}$ observou - se que ocorreu a inibição do crescimento de fungos em maças cortadas, o que poderá prolongar o seu tempo de vida de prateleira em condições naturais (Figura 3), conforme descrito por Assis ${ }^{17}$.

Observou-se que os frutos com cobertura de quitosana apresentaram uma coloração amarelada mais intensa que a situação controle, isto se deve a processos de oxidação de enzimas devido ao fato de que foi utilizado solução de ácido acético o que aumenta a oxidação.

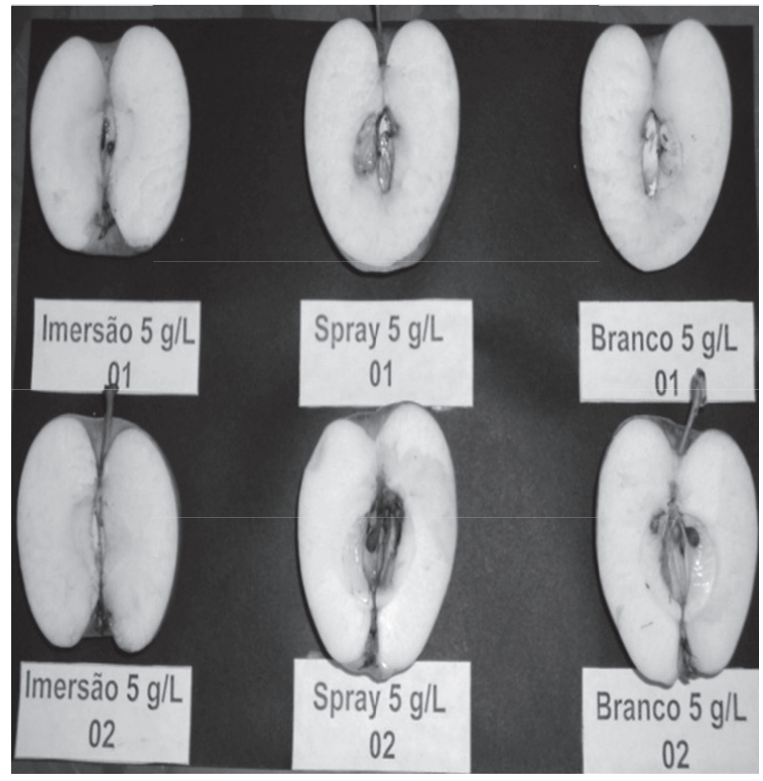

(a)

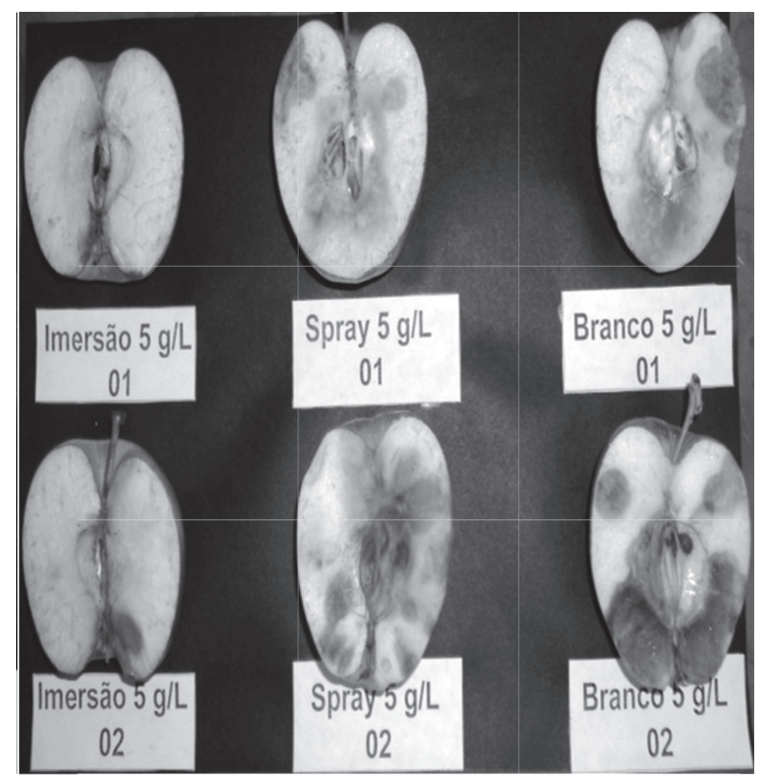

(b)

Figura 3. Ilustração da perda de massa da maça e análise microbiológica qualitativa do biofilme de $5 \mathrm{~g} / \mathrm{L}$. (a) Início e (b) ao final de 10 dias de armazenamento.

Espessura filmes e Permeabilidade ao vapor de água

A espessura dos filmes é uma variável fundamental para a caracterização de biofilmes, já que interfere 
significativamente em diversas propriedades dos mesmos. O controle da espessura dos filmes é importante para se avaliar a uniformidade desses materiais, a repetibilidade da medida de suas propriedades e a validade das comparações entre filmes. Conhecendose a espessura é possível obter informações sobre as propriedades de barreira ao vapor d'água do material e resistência mecânica ${ }^{41}$. Essa variação nas espessuras dos filmes biodegradáveis é decorrente do processo casting, no qual o polímero é dissolvido em meio ácido e vertido sobre uma superfície plana e, após a evaporação do solvente, o filme é removido por destacamento. Porém, a maioria dos filmes processados dessa forma é irregular quanto a sua espessura e heterogeneidade dependendo da massa aplicada além da concentração das soluções filmogênicas ${ }^{32,42,43}$.

Os filmes elaborados neste trabalho de acordo com diferentes concentrações de quitosana apresentaram variação em sua espessura, sendo o de menor espessura o filme de concentração de quitosana de $5 \%(0,036 \mathrm{~mm})$ e, o de maior espessura o de $20 \%$ de quitosana $(0,056 \mathrm{~mm})$, conforme mostra a Tabela 1.

Os filmes a base de polissacarídeos são hidrofílicos, o que resulta em pobre barreira ao vapor d' água. Segundo Park e Chinam ${ }^{44}$ a permeabilidade ao vapor de água em filmes hidrofílicos, como a base do polissacarídeo quitosana, pode variar com a espessura dos filmes devido às mudanças estruturais advindas do aumento da atividade de água causando o inchamento da matriz polimérica, afetando a estrutura do filme e provocando tensões internas e, por conseguinte, diminuindo a propriedade de barreira ao vapor d' água. Os resultados da permeabilidade à vapor referentes aos filmes de quitosana 5,10,15 e $20 \mathrm{~g} / \mathrm{L}$ encontram-se dispostos na Tabela 2.

Observa-se que a permeabilidade diminui progressivamente à medida que aumentou-se a concentração da solução de quitosana, porém todos os filmes de quitosana são bem permeáveis ao vapor de água, logo, eles podem ser aplicados no controle de migração de vapor de água, pois estes possuem boa propriedade de barreira ao oxigênio, dióxido de carbono e lipídeos, porém como filmes hidrocoloides não possuem boa barreira a vapores de água. Porém se observa Tal característica se deve a estrutura da quitosana, na qual há a predominância dos grupos amino caracterizados por ligações covalentes $(\mathrm{N}-\mathrm{H})$, na qual a eletronegatividade das ligações gera sítios de alta polaridade tornando assim favorável o rearranjo de moléculas de água em torno desses sítios. Essa característica estrutural, associada aos grupos acetamida, que também são polares e estão presentes na cadeia polimérica, caracterizam um material com alto grau de afinidade e retenção de água ${ }^{45}$.

Tabela 1. Resultados experimentais da Espessura ( $\mathrm{mm}$ ) de filmes elaborados com diferentes concentrações de quitosana.

\begin{tabular}{|c|c|c|c|c|}
\hline $\begin{array}{c}\text { Ensaio } \\
(\mathbf{m m})\end{array}$ & $\mathbf{5 g} / \mathbf{L}$ & $\mathbf{1 0 g} / \mathbf{L}$ & $\mathbf{1 5 g} / \mathbf{L}$ & $\mathbf{2 0 g} / \mathbf{L}$ \\
\hline E1 & 0,035 & 0,042 & 0,053 & 0,052 \\
\hline E2 & 0,022 & 0,043 & 0,060 & 0,055 \\
\hline E3 & 0,040 & 0,042 & 0,052 & 0,053 \\
\hline E4 & 0,040 & 0,047 & 0,050 & 0,055 \\
\hline E5 & 0,035 & 0,045 & 0,045 & 0,057 \\
\hline E6 & 0,040 & 0,040 & 0,050 & 0,057 \\
\hline E7 & 0,033 & 0,038 & 0,055 & 0,058 \\
\hline E8 & 0,030 & 0,038 & 0,045 & 0,052 \\
\hline E9 & 0,038 & 0,042 & 0,052 & 0,055 \\
\hline E10 & 0,037 & 0,040 & 0,047 & 0,063 \\
\hline Média & $\begin{array}{c} \pm, 035 \\
\pm\end{array}$ & $\begin{array}{c}0,042 \\
\pm\end{array}$ & $\begin{array}{c} \pm, 051 \\
\pm\end{array}$ & 0,056 \\
\pm \\
\hline
\end{tabular}

Tabela 2. Resultados experimentais da análise permeabilidade à vapor de filmes elaborados com diferentes concentrações de quitosana.

\begin{tabular}{|c|c|c|c|c|c|c|}
\hline Ensaio & $\mathbf{g} / \mathbf{t}$ & $\begin{array}{c}\text { Área } \\
\left(\mathbf{m m}^{\mathbf{2}}\right)\end{array}$ & $\begin{array}{c}\text { TVA } \\
\left(\mathbf{g ~ m}^{-2} \mathbf{h}^{-1}\right)\end{array}$ & $\begin{array}{c}\text { Espessura } \\
(\mathbf{m m})\end{array}$ & $\begin{array}{c}\Delta \mathbf{P} \\
(\mathbf{K p a})\end{array}$ & $\begin{array}{c}\mathbf{P V A} \\
\left(\mathbf{g} \cdot \mathbf{m m} \cdot \mathbf{h}^{-1} \cdot\right. \\
\left.\mathbf{m}^{-2} \cdot \mathbf{k P a}^{-1}\right)\end{array}$ \\
\hline $5 \mathrm{~g} / \mathrm{L}$ & 0,612 & 3,801 & 0,16101 & 0,035 & 3,167 & $1,8302 \cdot 10-3$ \\
\hline $10 \mathrm{~g} / \mathrm{L}$ & 0,467 & 3,801 & 0,12286 & 0,042 & 3,167 & $1,6294 \cdot 10-3$ \\
\hline $15 \mathrm{~g} / \mathrm{L}$ & 0,26 & 3,801 & 0,0684 & 0,051 & 3,167 & $1,1015 \cdot 10-3$ \\
\hline $20 \mathrm{~g} / \mathrm{L}$ & 0,239 & 3,801 & 0,06288 & 0,056 & 3,167 & $1,1118 \cdot 10-3$ \\
\hline
\end{tabular}

\section{TESTE DE BIODEGRADAÇÃO}

Os experimentos foram feitos em duplicata para os filmes de quitosana $5 \mathrm{~g} / \mathrm{L}$ e uma análise para o branco. A degradação microbiana ou biodegradação é um processo no qual as enzimas produzidas por microrganismos, degradam a matriz polimérica do polímero tanto em meio aeróbio quanto anaeróbio. O polímero é considerado 100 \% biodegradável quando sua conversão em nutrientes for completa e não gere resíduos tóxicos. 
Primeiramente realizou-se a análise de biodegradação dos filmes e posteriormente foi feita a análise do branco, no qual o húmus sem o filme biodegradável foi colocado no sistema de biodegradação para quantificar a liberação de gás carbônico da matéria orgânica presente no húmus.

Verificou-se ao longo de 10 dias consecutivos com um intervalo de aproximadamente 24 horas a liberação irregular de $\mathrm{CO} 2$, porém crescente até quinto dia, após ocorreu um declínio (Figura 4). A massa de gás carbônico produzida da decomposição da matéria orgânica foi quantificada a partir da quantificação do precipitado de carbonato de bário formado (equação 1).

$$
1 \mathrm{CO}_{2}+1 \mathrm{Ba}(\mathrm{OH})_{2} \rightarrow 1 \mathrm{BaCO}_{3}
$$

Nodécimodiafoiainda observadomacroscopicamente parte do filme de quitosana, sugerindo que a degradação do filme de quitosana não é rápida, sendo necessário mais que dez dias para a decomposição total do filme.

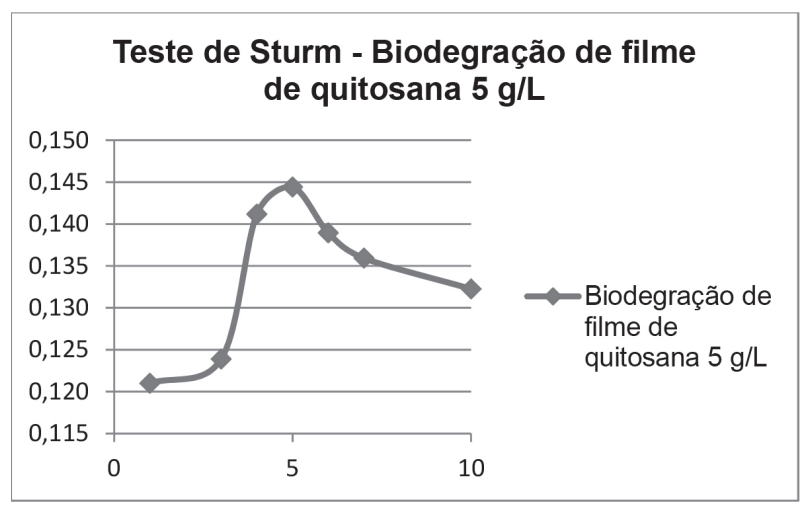

Figura 4. Teste de Sturm - Quantidade de CO2 liberado por dia para o filme de quitosana $5 \mathrm{~g} / \mathrm{L}$.

\section{Considerações Finais}

Os filmes de quitosana apresentaram espessura variada e a espessura aumentou da menor concentração para a maior concentração da solução de quitosana ( 5 para $20 \mathrm{~g} / \mathrm{L}$ ). Foi confirmado o caráter hidrofílico da quitosana, na qual independente da concentração a taxa de absorção de água é elevada, porém se observa que a permeabilidade ao vapor de água diminui progressivamente à medida que se aumenta a concentração da solução de quitosana. A partir do teste de biodegradação observou-se que ocorreu degradação parcial do filme de quitosana no período de dez dias.

A aplicação de filme de quitosana em maçãs concluise que a aplicação da quitosana teve ação significativa na extensão do tempo de vida da maçã, isto é, a cobertura de quitosana atuou como barreira aos processos metabólicos de respiração e transpiração do fruto, além da conservação contra fungos e bolores quando comparados a maçã sem filme de quitosana.

\section{Referências Bibliográficas}

1. Tanada-Palmu, P.S.; Grosso, C.R.F. Boletim do CEPPA, 2002, 20(2), 291.

2. Tanada-Palmu, P.S.; Grosso, C.R.F. Res. Adv. in Agric. \& Food Chem. 2002, 3, 53.

3. Rao, M.S.; Kanatt, S.R.; Chawla, S.P.; Sharma, A. Carbohydr. Polym. 2010, 82(4), 1243.

4. Dotto, G. L. et al. Congresso de Iniciação Científica, Universidade Federal do Rio Grande, 2008.

5. Borderías, A.J.; Sánchez-Alonzo, I.; Pérez-Mateos, M. Trends Food Sci. Tech., 2005, 16, 458.

6. Chien, P-J.; Sheu, F.; Lin, H-R.; Food Chem., 2007, 100, 160.

7. NATIONAL TOXICOLOGY PROGRAM - Testing status of agents at National Toxicology Program: Department of Health and Human Services. Disponível em: $<$ http://ntp.niehs.nih. gov/?objectid=BD3BB7C6-123F-7908-7BB099AF2C319611 >. Acessado em maio de 2012.

8. FDA - FOOD AND DRUG ADMINISTRATION. Disponível: em: <http://www.accessdata.fda.gov/scripts/fen/gras_notices/ grn000073pdf $>$. Acessado em maio de 2012.

9. Arai, K.; Kinumaki, T.; Fujita, T. Bull. Tokai. Region. Fish. Res. Lab. 1968, 56, 89.

10. Fai, A. E. C.; Stamford, T. C. M.; Stamforde, T. L. M. Revista Iberoamericana de Polímeros, 2008, 9(5), 435.

11. Tanada-Palmu, P. S.; Proença, P.S.P.; Trani, P. E; Passos, F. A; Grosso, C. R. F. Bragantia. 2005, 64(2), 291.

12. Cia, P.; Benato, E. A.; Pascholati, S. F.; Oliveira, G., E. Bragantia. 2010, 69(3), 745.

13. Bautista-Baños, S.; Hernádez-Lópes, M.; Bosquez-Molina, E.; Wilson, C.L. Crop Protection. 2003, 22(9), 1087.

14. El Ghaouth, A.; Arual, J.; Ponnamapalam, R.; Boulet, M. J. Food Sci. 1991, 56, 1618.

15. Romazzi, G.; Nigro, F.; Ippolito, A.; Venere, D. D.; Salerno, M. Food Microb. and Saf. 2002, 67(5), 1862.

16. Camili, E.C., Benato, E.A., Pascholati, S. F., Cia, P. Summa Phytopathologica. 2007, 33(3), 215. 
17. Assis, O.B.G.; Alves, H.C. Comunicado Técnico - Embrapa instrumentação Agropecuária, 2002, 5p.

18. Stamford, N. P.; Stamford, T. C.. M.; Berger, L. R. R. Revista Iberoamericana de Polímeros. 2011,12(4).

19. El Ghaouth. A.; Arul, J.; Grenier, J.; Asselin, A. Phytopathology, 1992, 82(4), 496

20. El Ghaouth, A.; Arul, J.; Wilson, C.; Benhamou, N. Postharvest Biology and Technology, 1997, 12(2), 183.

21. Reddy, M.V.B.; Belkacemi, K.; Corcuff, R.; Castaigne, F.; Arul, J. Postharvest Biology and Technology. 2000, 20, 39.

22. Devlieghere, F.; Vermeulen, A.; Debevere, J. Food Microbiology. 2004, 21(6), 703.

23. Jiang, Y.; Li, Y. Food Chemistry. 2001, 73, 139.

24. Hardwiger, L.A.; Beckman, J.M.; Adams, M.J. Plant Physiology. 1981, 67, 170.

25. El Ghaouth, A.; Smilanick, J.L.; Wilson, C.L. Postharvest Biology and Technology. 2000, 19, 103.

26. Rappussi-da-Silva, M.C.C. Dissertação de mestrado. Escola Superior de Agricultura "Luiz de Queiroz", Universidade de São Paulo, 2006.

27. Cia, P. Tese de doutorado. Escola Superior de Agricultura. "Luiz de Queiroz", Universidade de São Paulo, 2005.

28. Pak, H.A.; Rasim, S.; Manning, M.A; Fullerton, R.A. Plant Protection Conference, 1998,123.

29. Mazaro, S.M.; Gouvea A.; Citadin, I. Congresso Iberoamericano de Tecnologia Pós-colheita e Agroexportação, 2005.

30. El Ghaouth, A. et al., Physiological and Molecular Plant Pathology. 1994, 44(6), 417.

31. Di Piero, R.M.; Garda, M.V. Pesquisa Agropecuária Brasileira. 2008, 43, 1121 .

32. - Monterrey-Quintero, E. S. Dissertação de Mestrado, Faculdade de Zootecnia e Engenharia de Alimentos, Universidade de São Paulo, 1998.

33. Vicentini, N. M. Tese de doutorado, Faculdade de Ciências Agronômicas, Universidade Estadual Paulista - UNESP, 2003.

34. AMERICAN SOCIETY FOR TESTING AND MATERIALS - ASTM. Standard test method for water vapor transmission of material - E96-95, Annual book of ASTM, Philadelphia, PA: American Society for Testing and Materials. 1995.
35. AMERICAN SOCIETY FOR TESTING AND MATERIALS - ASTM Standard Test Method for Determining Aerobic Biodegradation of Plastic Materials Under Controlled Composting Conditions - D 5338 - 98. Philadelphia (USA): ASTM, 1998.

36. Rosa, D. S.; Chui, Q. S. H.; Pantano-Filho, R.; Agnelli, J. A. M. Polímeros: Ciência e Tecnologia. 2002, 12(4), 311.

37. Hernandez-Munoz, P.; Almenar, E.; Ocio, M. J.; Gavara, R. Postharvest Biology and Technology. 2006, 39, 247.

38. Han, L. K.; Kimura, Y.; Okuda, H. Int J Obes Relat Metab Disord. 1999, 123, 174.

39. Zhang, D.; Quantick, P. C. Postharvest Biology and Technology. Amsterdam, 1997, 12, p. 195.

40. Assis, O.B.G.; SILVA, V.L. Polímeros: Ciência e Tecnologia. 2003, 13(4), 223.

41. Oliveira, T. M. Dissertação de Mestrado, Universidade Federal de Viçosa, 2007.

42. Sobral, P. J. A. Ciência \& Engenharia. 1999, 8(1), 60.

43. Mali, S. Tese de Doutorado, Centro de Ciências Agrárias, Universidade Estadual de Londrina, 2002.

44. Park, H. J.; Chinnan, M. S. J. Food Eng. 1995, 25, 497.

45. Signini, R.; Campana-Filho, S. P. Polímeros: Ciência. e Tecnologia. 2001, 11(4), 58.

\section{Tayane H. Siqueira \& Roberta Signini*}

${ }^{1}$ Universidade Estadual de Goiás, Caixa Postal 459, CEP 75001-970, Anápolis, GO.

*e-mail: roberta.signini@ueg.br 